\title{
Phenotypic and molecular characterization of Plectosphaerella cucumerina on bamboo from Iran
}

\author{
Arzanlou $\mathbf{M}^{1^{*}}$, Torbati $\mathbf{M}^{2}$ and Khodaei $\mathrm{S}^{3}$ \\ ${ }^{1}$ Associate Professor of Plant Pathology and Mycology, Plant Protection Department, Faculty of Agriculture, \\ University of Tabriz, PO Box: 5166614766, Iran. \\ ${ }^{2}$ MSc Student of Plant Pathology, Plant Protection Department, Faculty of Agriculture, University of Tabriz, PO Box: \\ 5166614766, Iran. \\ ${ }^{3}$ PhD Student of Plant Pathology, Plant Protection Department, Faculty of Agriculture, University of Tabriz, PO Box: \\ 5166614766, Iran.
}

Arzanlou M, Torbati M, Khodaei S 2013 - Phenotypic and molecular characterization of Plectosphaerella cucumerina on bamboo from Iran. Mycosphere 4(3), 647-651, Doi 10.5943/mycosphere/4/3/16

\begin{abstract}
In a survey on the mycobiota associated with bamboo species in Iran, during 2010 a phialidic hyphomecete was recovered from apparently healthy bamboo stems in Assalouyeh (Bushehr province). Fungal isolates were identified as Plectosphaerella cucumerina based on morphological data. The identity of the species was further confirmed using sequence data from ITS-rDNA region. A phylogeny inferred using sequence data from ITS-rDNA region placed our isolate together with $\mathrm{Pa}$. cucumerina from the other hosts in GenBank. This is the first record for the genus Plectosphaerella and first report on the occurrence of P. cucumerina on bamboo in Iran.
\end{abstract}

Key words - Endophyte - Plectosphaerellaceae - phialide

\section{Introduction}

Bamboo belongs to the family Poaceae comprising some 80 genera with estimated number of 1000 species, occurring in tropical, subtropical and temperate climates (Dransfield and Widjaja 1995). Bamboos are utilized intensively for a wide range of purposes in tropics such as building materials for houses, handicraft, paper, ect. (Dransfield and Widjaja 1995). A rich diversity of fungal species are known from bamboos worldwide. Until now more than 1100 fungal species have been reported to occur on bamboo (Hyde et al. 2002). Fungal species occurring on bamboo are commonly known as bambusicolous fungi. Several bamboo species occur in the mainland of Iran; however, there is no data available on the diversity of fungal species on this host in Iran. Recently Arzanlou and Khodaei (2012) have described a new species of Aureobasidium Viala \& Boyer namely A. iranianum Arzanlou \& S. Khodaei from a bamboo species in Iran. With this paper we describe Plectosphaerella cucumerina (Lindf.) W. Gams as new record for mycobiota of Iran from a bamboo species.

\section{Methods}

\section{Collection of isolates, morphological and cultural studies}

During a field excursion to the Assalouyeh (Bushehr province) region in southern parts of 
Iran, samples were collected from apparently healthy Bambusa sp. For the isolation, bamboo stems were cut into small pieces, surface sterilized with $70 \%$ ethanol, rinsed two times with sterilized distilled water, dried on sterile filter paper and plated on acidified potato dextrose agar (PDA; Himedia, India). Pure cultures were established from sporulating cultures using a single spore technique. Colony morphology including colour, shape and growth rate was determined after $14 \mathrm{~d}$ of incubation on PDA and malt extract agar (MEA; Himedia, India) at $25^{\circ} \mathrm{C}$ in darkness according to the protocol explained by Carlucci et al. (2012). Microscopic characters were examined from slide cultures prepared according to the method described by Arzanlou et al. (2007). A small block of the PDA $(20 \times 20 \times 10 \mathrm{~mm})$ was placed on the clean and sterile microscope slide and inoculated at four points using a sterile inoculation needle. A cover slip was then gently placed on the block and the apparatus was placed on a U-shaped glass rod in a sterile Petri dish containing $5 \mathrm{ml}$ sterile water which served as moist chamber. After $14 \mathrm{~d}$ of incubation at $25^{\circ} \mathrm{C}$ in the dark, the cover slip was gently removed and mounted in lactic acid and undisturbed fungal structures were examined using a light microscope. Thirty measurements were made for each microscopic structure where possible and $95^{\text {th }}$ percentiles were determined for the measurements with the extremes given in parentheses. Photographs were captured using a light Olympus-BX41 microscope with an Olympus digital camera system (DP 25) and software to analyze photographs. The cultures were deposited in the living Culture Collection of Tabriz University (CCTU), Tabriz, Iran.

\section{DNA extraction, amplifcation and phylogenetic analysis}

For molecular characterization of the isolates, fungal genomic DNA was extracted from 14d old cultures grown on PDA plates following the protocol of Moller et al. (1992). The 3' end of the $18 \mathrm{~S}$ rRNA gene, ITS1, 5.8S rDNA, ITS2 and the 5' end of 28S rRNA gene regions was amplified using the primer set ITS1 and ITS4 (White et al. 1990). Polymerase chain reaction amplification was performed on a GeneAmp PCR System 9700 (Applied Biosystems, Foster City, CA). Reaction

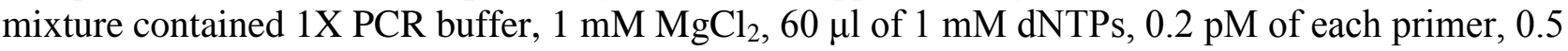
$\mathrm{U}$ of Taq polymerase, $0.5 \mu \mathrm{L}$ DSS, and 10-15 ng of fungal genomic DNA. The final reaction volume was adjusted to $12.5 \mu \mathrm{l}$ by adding sterile distilled water. Cycling conditions consisted of an initial cycle for $5 \mathrm{~min}$ at $95^{\circ} \mathrm{C}$, followed by 40 cycles of $30 \mathrm{~s}$ at $94^{\circ} \mathrm{C}, 30 \mathrm{~s}$ at $52^{\circ} \mathrm{C}$ and $1 \mathrm{~min}$ at $72^{\circ} \mathrm{C}$, followed by a final extension cycle of $7 \mathrm{~min}$ at $72^{\circ} \mathrm{C}$. PCR products were sequenced using the BigDye Terminator v3.1 (Applied Biosystems, Foster City, CA) Cycle Sequencing Kits and subsequently analyzed on an ABI Prism 3700 (Applied Biosystems, Foster City, CA) according to the recommendations of the seller. Raw sequence files were edited manually by using SeqMan ${ }^{\mathrm{TM}} \mathrm{II}$ (DNASTAR, Madison, Wisconsin, USA) and a consensus sequence was generated for each of the sequences. Sequences were subjected to Blast search analysis at NCBI's GenBank nucleotide database for sequence similarity and sequences with high degrees of similarity were downloaded. The sequences obtained in this study were aligned together with the sequence data from GenBank by using ClustalW algorithm implemented in MEGA 5 (Tamura et al. 2011). A phylogenetic tree was constructed using neighbor-joining method (kimura-2 as substitution model; gaps treatment as pairwise deletion). Transitions and transversions (with the equal ratio) were included in the analysis. The support of the internal nodes of the tree was evaluated by the bootstrap method with 10,000 replicates. The phylogenetic tree was rooted to Colletotrichum acutatum (GenBank accession number: AJ301913.1).

\section{Results}

\section{Morphology}

Fungal isolates were identified as Plectosphaerella cucumerina (Lindf.) W. Gams based on morphological and molecular examination. Colonies on PDA and MEA were flat, slimy, appressed, with sparse aerial mycelium, buff to salmon pink. Mycelium hyaline, branched, septate, 3-4 $\mu \mathrm{m}$ wide, with numerous anastomosis, forming hyphal coils. Conidiophores solitary, hyaline, smooth, thin-walled, unbranched or rarely irregularly branched. Conidiogenous cells phialidic, 

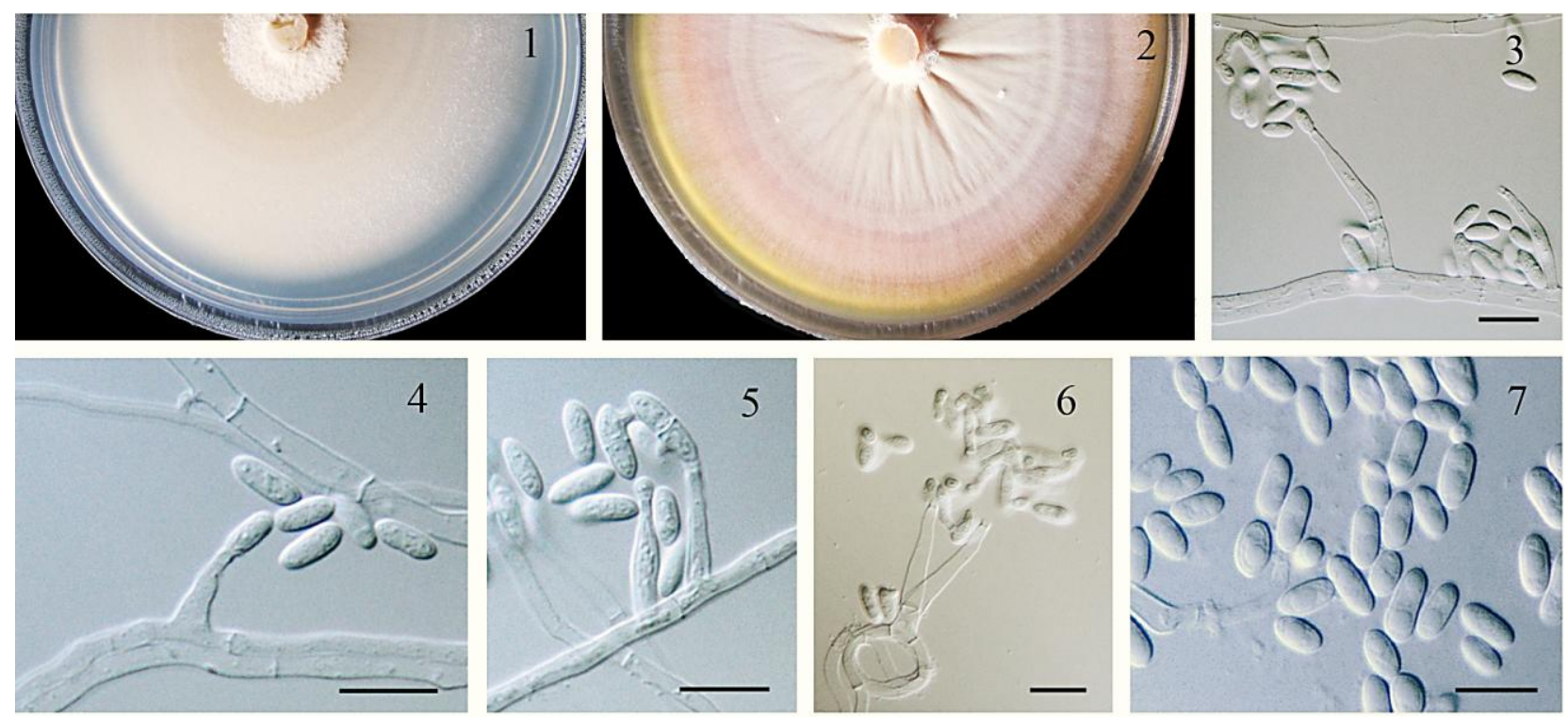

Figs 1-8 - Plectosphaerella cucumerina. 1,2 Colonies on PDA and MEA after $14 \mathrm{~d}$ at $25^{\circ} \mathrm{C} .3,4$ solitary conidiophores. 5 Anastomosis between conidia. 6 Hyphal coil with phialides. 7 Conidia. - Scale bars $=10 \mu \mathrm{m}$.

determinate, discrete, smooth, solitary, formed on the hyphal coils, phialides aseptate, occasionally 1-saptate near the base, sometimes branched at tip, gradually tapering to the apex, sometimes crooked, widest at the base, (10-) 12-40 (-45) $\times(1-) 2-3.5(-4) \mu \mathrm{m}$, periclinal thickening conspicuous, collarette cylindrical, 1.5-2 $\mu \mathrm{m}$ deep. Conidia hyaline, aggregating in slimy heads, ellipsoid tapering to rounded ends, amero (aseptate) to didymo (1-septate), (3-) 5.3-6.3 (-9) $\times(2-)$ 3-3.58 (-5) $\mu \mathrm{m}$, anastomosis observed between conidia. Chlamydospore absent (Figs 1-7). The morphological characteristics were in full agreement with the description of $P$. cucumerina (Carlucci et al. 2012).

Material examined - IRAN, Bushehr province, Kangan, Assaluyeh, stems of Bambusa sp. (Poaceae), 10 June, 2009. Living culture CCTU 457, CCTU 458).

\section{DNA Phylogeny}

Blast search of ITS-rDNA against GenBank nucleotide (nr) showed 99-100 percent similarity with $\mathrm{Pa}$. cucumerina isolates from different hosts. A phylogeny inferred using sequence data from ITS-rDNA clustered our isolates together with other Pa. cucumerina isolates (Fig 2). The sequences are available in GenBank with the accession numbers KC845226 and KC845227.

\section{Discussion}

Based on a combination of morphological and sequence data the fungal isolates recovered from Bambusa sp. were identified as Pa. cucumerina. The genus Plectosphaerella was first introduced by Klebahn in 1929 with $\mathrm{Pa}$. cucumeris to accommodate fungal isolates recovered from cucumber plants (Carlucci et al. 2012). Pa. cucumeris was later considered to be conspecific with Venturia cucumerina. A new combination as Pa. cucumerina was made by Gams (Domsch et al. 2007). Anamorphic state of Pa. cucumerina was first housed in the genus Fusarium as $F$. tabacinum. Palm et al. (1995) described the genus Plectosporium for the anamorph of $P a$. cucumerina. Plectosphaerella has phylogenetic affinity with the order Hypocreales. Zare et al. (2007) erected the family Plectosphaerellaceae as sister clade to Glomerellaceae, which accommodates Plectosphaerella (as Plectosporium) together Acrostalagmus, Gibellulopsis, Musicillium and Verticillium.

Since the description of Plectosporium for asexual state of Plectosphaerella a number of new Plectosporium species have been described (Pitt et al. 2004, Antignani et al. 2008, Duc et al. 2009). However, considering the recent changes in naming fungal species (one fungus $=$ one 


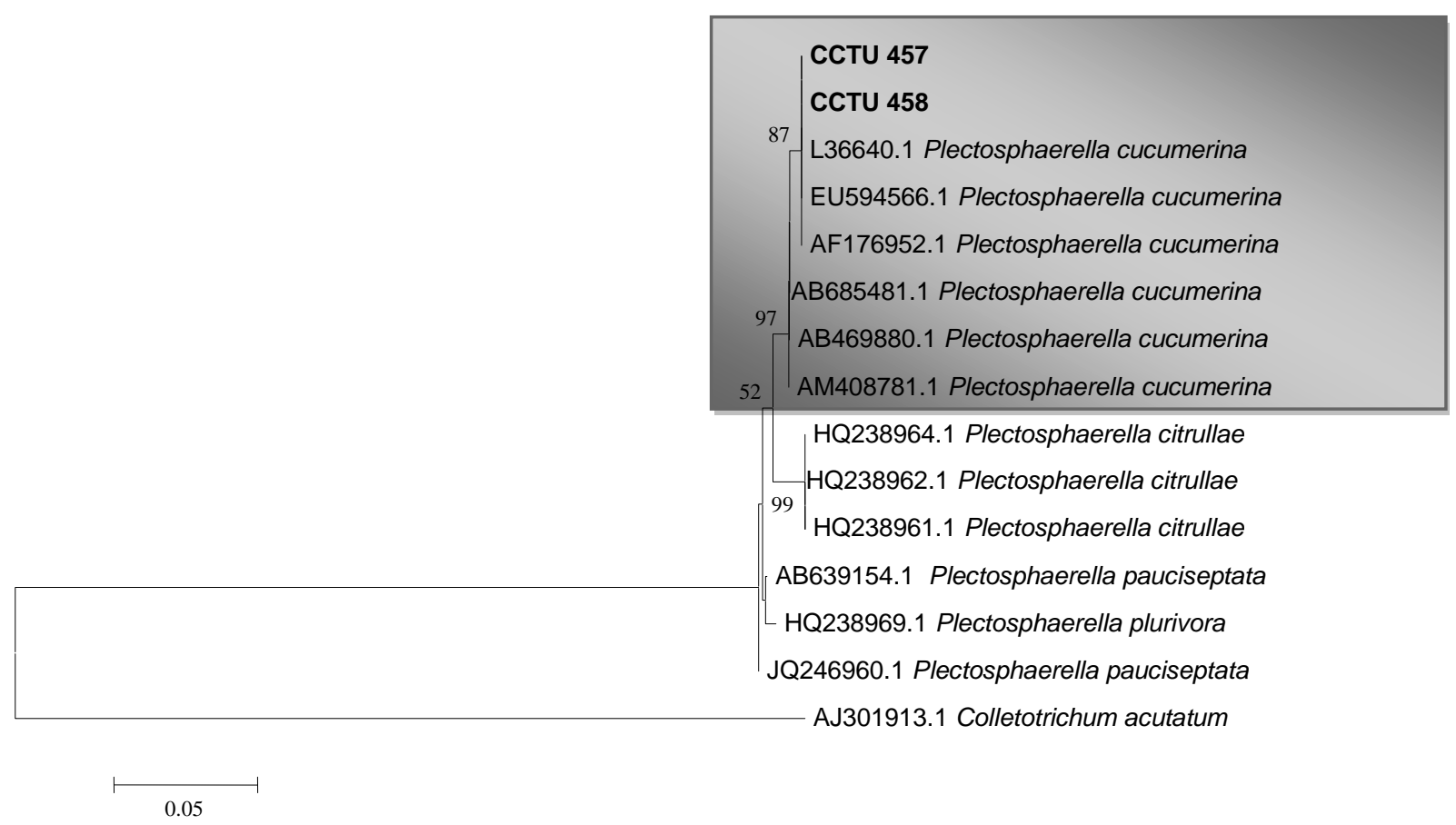

Fig. 2 - A neighbor-joining phylogenetic tree obtained from the ITS regions and 5.8S rDNA sequence data. Bootstrap support values from 10,000 replicates are indicated on the nodes. The tree was rooted to Colletotrichum acutatum. The scale bar indicates 0.05 substitutions per site.

name), the teleomorph genus name Plectosphaerella, have been applied for this genus and new combinations have been proposed for Plectosporium species in Plectosphaerella (Carlucci et al. 2012). Plectosphaerella spp can be differentiated based on morphological criteria of their asexual states such as the ratio of septate conidia, conidial shape and dimensions and presence or absence of chlamydospores (Pitt et al. 2004, Duc et al. 2009, Antignani et al. 2008, Carlucci et al. 2012). However, considerable amounts of variation have been observed in cultural and morphological characteristics between isolates of Pa. cucumerina (Palm et al. 1995, Carlucci et al. 2012). Sequence data from ITS-rDNA have widely been used for species delineation in this genus (Carlucci et al. 2012). The same as morphology there seems to be considerable amount of variation in ITS region among Pa. cucumerina isolates (Carlucci et al. 2012). Whether Pa. cucumerina represents an example of species complex with several cryptic species remains to be studied using multigene phylogenetic approaches.

The genus Plectosphaerella currently comprises eight species and species complexes (Carlucci et al. 2012). Species in this genus exhibit diverse life styles as plant pathogens causing fruit, root, collar rot and collapse on several plant species, endophytes, colonizing plant tissues without causing visible symptoms and some species with nematophagous behavior. Pa. cucumerina has been isolated from the egg masses of Meloidogyne hapla Chitwood on tomato crops in Belgium (Yu \& Coosemans 1998) and has been shown to reduce field populations of potato cyst nematodes (PCN) Globodera rostochiensis Wollenweber and Globodera pallida Stone up to $60 \%$ after incorporation into alginate pellets (Atkins et al. 2003).

In the present study $\mathrm{Pa}$. cucumerina isolates were recovered from the stems of apparently healthy bamboos and no attempt was made to perform Koch's postulates. Whether the isolates are pathogenic on bamboo or have endophytic nature on this host remains to be studied. In Iran potato cyst nematodes have recently become as emergent threat for potato industry; such that the potential of $\mathrm{Pa}$. cucumerina obtained in this study in biological control of this serious pest of potato can be a subject for future studies. 


\section{Acknowledgements}

The authors are grateful to the Research Deputy of the University of Tabriz and the Studienstiftung für mykologische Systematik und Ökologie for financial support.

\section{References}

Arzanlou M, Khodaei S. 2012 - Aureobasidium iranianum, a new species on bamboo from Iran. Mycosphere 3, 404-408.

Arzanlou M, Groenewald JZ, Gams W, Braun U, Shin HD, Crous PW. 2007 - Phylogenetic and morphotaxonomic revision of Ramichloridium and allied genera. Studies in Mycology 58, 57-93.

Antignani V, Gams W, Marziano F. 2008 - Plectosporium delsorboi nov. sp., a pathogen of Curcuma, Zingiberaceae. Nova Hedwigia 86, 209-214.

Atkins SD, Clark IM, Sosnowska D, Hirsch PR, Kerry BR. 2003 - Detection and Quantification of Plectosphaerella cucumerina, a potential biological control agent of potato cyst nematodes, by using conventional PCR, real-time PCR, selective media, and baiting. Applied and Environmental Microbiology 69, 4788-4793.

Carlucci A, Raimondo ML, Santos J, Phillips AJL. 2012 - Plectosphaerella species associated with root and collar rots of horticultural crops in southern Italy. Persoonia 28, 34-48.

Domsch KH, Gams W, Anderson TH. 2007 - Compendium of Soil Fungi. IHW-Verlage, Eching, Germany, 399-400.

Dransfield S, Widjaja EA (Editors). 1995 - Plant Resources of South-East Asia No 7. Bamboos. Backhuys Publishers, Leiden. 189 pp.

Duc PM, Hatai K, Kurata O, Tensha K, Uchida Y, Yaguchi T, Udagawa SI. 2009 - Fungal infection of mantis shrimp (Oratosquilla oratoria) caused by two anamorphic fungi found in Japan. Mycopathologia 167, 229-247.

Hyde KD, Zhou DQ, Dalisay T. 2002 - Bambusicolous fungi: A review. Fungal Divers 9: 1-14.

Moller EM, Bahnweg G, Geiger HH. 1992 - A simple and efficient protocol for isolation of high molecular weight DNA from filamentous fungi, fruit bodies, and infected plant tissues. Nuclear Acid Research 20, 6115-6116.

Palm ME, Gams W, Nirenberg HI. 1995 - Plectosporium, a new genus for Fusarium tabacinum, the anamorph of Plectosphaerella cucumerina. Mycologia 87, 397-406.

Pitt WM, Goodwin SB, Ash GJ, Cother NJ, Cother EJ. 2004 - Plectosporium alismatis comb. nov., a new placement for the Alismataceae pathogen Rhynchosporium alismatis. Mycological Research 108, 775-780.

Tamura K, Nei M, Kumar S. 2011- MEGA5: Molecular evolutionary genetics analysis using maximum likelihood, evolutionary distance, and maximum parsimony methods. Molecular Biology and Evolution 28, 2731-2739.

White TJ, Bruns TD, Lee SB, Taylor JW. 1990 - Amplification and sequencing of fungal ribosomal RNA genes for phylogenetics, pp. 315-322. In: PCR-Protocols and Applications A Laboratory Manual (Innis N, Gelfand D, Sninsky J, White TC, eds). Academic Press, New York.

Yu Q, Coosemans J. 1998 - Fungi associated with cysts of Globodera rostochiensis, G. pallida, and Heterodera schachtii, and egg masses and females of Meloidogyne hapla in Belgium. Phytoprotection 79, 63-69.

Zare R, Gams W, Starink-Willemse M, Summerbell RC. 2007-Gibellulopsis, a suitable genus for Verticillium nigrescens, and Musicillium, a new genus for $V$. theobromae. Nova Hedwigia 85, 463-489. 